recalls that a few years before the Second World War the late Col. Balfour, of Dawyck, set ptarmigan eggs below a grouse on high ground on Upper Tweed, and the Duchess of Montrose made the same experiment on Goat Fell on Arran, where the ptarmigan at one time nested. Neither experiment was, I think, successful.

The two volumes are handsomely produced. There are two beautiful coloured frontispieces by G. E. Lodge and excellent photographs by Robert M. Adam, Eric Hosking and others.

No student of birds can afford to be without this work.

SETON GORdoN

\section{CHEMISTRY OF STARCH}

Starch and its Derivatives

By J. A. Radley. (Monographs on Applied Chemistry, Vol. 11.) Third edition, revised. Vol. 1. Pp. xi+510. (London : Chapman and Hall, Ltd., 1953.) 65s. net.

$\mathrm{T}$ HE appearance of a third edjtion of this monograph indicates that its usefulness is well established. Considerable advances have been made in starch chemistry since the second edition appeared in 1943, and this has necessitated large sections of the book being rewritten. The author has, furthermore, invited a number of distinguished collaborators -including several from the United States-to write the chapters in their own specialized fields of investigation. The subject-matter covered has thus been expanded while at the same time an authoritative point of view has been maintained; but two volumes now replace the original one.

As in previous editions, both fundamental and technical aspects of starch chemistry are covered. The general method of presentation has been retained. Each chapter tends to be a review article and there is inevitably some overlapping, although the book presents a uniform appearance. The list of references accompanying each chapter covers the literature to about the end of 1950 .

The first volume is divided into two parts, of which the first deals with the structure, properties and reactions of starch, while the second covers amylases and their action. After a short historical introduction, there is an account by S. Peat of the enzymes involved in the synthesis and degradation of starch. This complex field is presented in a clear and concise manner. The fundamental chemical evidence for the structure of starch and its components is summarized in an excellent chapter by L. Hough and J. K. N. Jones. Physical properties such as swelling and gelatinization are also reviewed, with an emphasis on technical aspects. The longest and most complete chapter in the book is that on the starch fractions by T. J. Schoch. This provides a critical review of recent methods for separating, purifying and characterizing amylose and amylopectin. Many useful experimental data are incorporated. The physical properties of the two fractions are also discussed. In addition to an unusually long list of references (437, with the titles of the papers included) a cross-index of subjects is given. The significance of nitrogen and phosphorus in interpreting the behaviour of starch is next discussed; but little recent work is mentioned. An interesting account (by R. L. Whistler) of the phenomenon of retrogradation follows. A chapter discussing the hydrogen-bond by G. V. Caesar is followed by a review of the starch-iodine reaction. R. M. Hixon and B. Brimhall have written a chapter which reviews for the first time the chemistry of the waxy-cereals and starches.

The remainder of the first part deals with more technical aspects of starch chemistry. After a review on dextrins and dextrinization (G. V. Caesar), a comprehensive account is given by E. F. Degering of the preparation and physical and mechanical properties of the ethers and esters of starch. Inorganic and oxidized derivatives of starch are discussed by the same author. In Part 2, the preparation and mode of action of the amylases used in the starch industry are reviewed in a comprehensive manner with emphasis on the technical aspects.

The first volume of the new edition can be seen to incorporate much interesting new material, and should appeal to both the academic and industrial worker with an interest in starch chemistry.

$$
\text { E. L. HrRst }
$$

\section{CULTURAL ANTHROPOLOGY}

\section{The Nature of Culture}

By A. L. Kroeber. Pp. $x+438$. (Chicago: University of Chicago Press; London : Cambridge University Press, 1952.) 49s. net.

NAN can be viewed, as Prof. C. Lévi-Strauss has 1 recently pointed out, either as a tool-making animal or as a social animal. In dealing with primitive man, one's view on this matter determines whether one is a cultural anthropologist (the predominant school in the United States) or a social anthropologist (foremost in Britain).

Prof. A. L. Kroeber, the doyen of American anthropologists, over half a century ago placed himself firmly among those who regard man's tool-making capacities as the basis for a scientific study of mankind. Since then, his copious, but always scholarly and polished, writings have added immeasurably to all the various fields of anthropology, but particularly to the idea of culture. Anthropology without Kroeber would be the poorer ; cultural anthropology without Kroeber would indeed be poverty-stricken.

The present book is Prof. Kroeber's own editing of fifty of his articles and essays (some of them pared of extraneous material) centring around the notion of culture; each essay is accompanied by short "programme notes" of the circumstances of its composition, and the author's assessment as of late 1951 . The essays are grouped into five sections of which the first and the last, "Theory of Culture" and "History and Process of Civilization", are of greatest general interest. The other three sections-"Kinship and Social Structure", "On American Indians", and "Psychologically Slanted"-are of equally great interest to the professional reader, but probably of less to the non-anthropologist.

Prof. Kroeber's appointed task has been the con. ceptual separation of culture from the organism, the psyche and society. Culture, to him, is "superorganic". Just as reducing organic phenomena to inorganic terms tells us a great deal about them, but makes us lose sight of the all-important idea of 'life', so reducing cultural phenomena to organic or psychological factors tells us a great deal about them, but makes us lose sight of their equally important and illuminating aspects which are specifically cultural. To watch this idea develop from the outcry of 1917 ("The Superorganic") against the followers of Herbert Spencer who see cultural evolution as a continuation 